\title{
Learned variability
}

\author{
PATRICIA D. STOKES \\ Columbia University, New York, New York
}

\begin{abstract}
Potential contributors to sustained levels of variability in the topography of the rat's barpress were investigated in two experiments. Behavior was classified into discretely defined components, and changes in components and their sequential organization were analyzed. Experiment 1 showed that topographic variability in the rat is modulated by shifts in reinforcement schedules. Variability decreased between either dipper training or extinction and continuous reinforcement (CRF), and increased between $\mathrm{CRF}$ and extinction. Once the press was acquired, variability did not change if the schedule (CRF) did not change. Experiment 2 showed that, regardless of subsequent changes in topographic requirements, rats initially shaped to press under more stringent criteria sustained higher levels of variability during $\mathrm{CRF}$, but not during extinction, than rats shaped with less stringent criteria. The results suggest that subjects learn not only what to do during reinforcement but also how differently or variably to do it.
\end{abstract}

Some individuals are consistently more variable in their behavior than others. One guinea pig either brushes or taps a latch prior to opening it; another always opens it in the same way (Muenzinger, Koerner, \& Irey, 1929). One child uses three different strategies to do simple addition; another employs six strategies to solve the same problems (Seigler, 1994; Seigler \& Jenkins, 1989). The artists Matisse and Motherwell produced images using paint or pen or colored cut papers. Less creative individuals rarely, if ever, change or combine mediums. Why? Could these kinds of persistent variability differences reflect learning?

We know a great deal about how changes in variability follow changes in reinforcement schedules or response requirements, but little about consistency. Variability tends to decline during continuous reinforcement (CRF) (Antonitis, 1951; Guthrie \& Horton, 1946; Lachter \& Corey, 1982; Notterman, 1959; Schwartz, 1982a, 1982b; Vogel \& Annau, 1973) and to increase relative to CRF during either extinction or intermittent schedules (Eckerman \& Lanson, 1969; Tatham, Wanchisen, \& Hineline, 1993; but see Herrnstein, 1961). Variability increases

This paper is based on a doctoral dissertation submitted to the Graduate School of Arts and Sciences of Columbia University in partial fulfillment of the requirements for the $\mathrm{PhD}$. It was presented at the meeting of the Eastern Psychological Association in Boston, 1992. The author wishes to thank Peter Balsam, her advisor, for making this work possible; James Deich, Robin Garfinkel, Salvatore Pitruzzello, and Joseph Schwartz for their statistical assistance; Christina Kozma, Amy Lazev, Anat Reschke, Octavia Wong, and Jordanna Zanger for running and coding the experiments. Also greatly appreciated are Allen Neuringer's detailed comments on an earlier version of this manuscript. Address correspondence to the author at Department of Psychology, Barnard College, Columbia University, New York, NY 10027.

-Accepted by previous editor, Vincent M. LoLordo when a response criterion specifies doing something new (Holman, Goetz, \& Baer, 1977; Pyror, Haag, \& O'Reilley, 1969) or doing something differently (Blough, 1966; Bryant \& Church, 1974; Christenson, Guilford, \& Wilson, 1957; Joyce \& Chase, 1990; Maltzman, 1960; Morris, 1987; Neuringer, 1986, 1991, 1993; Royce, 1898; Schoenfeld, Harris, \& Farmer, 1966; Wong, 1977). The greater the difference from prior responding required, the higher the variability (Machado, 1989, 1992; Page \& Neuringer, 1985).

A promising area in which to begin investigating why some individuals are consistently more variable than others is reinforcement history, specifically, the initial conditions under which learning takes place. Response rate (Alleman \& Zeiler, 1974; Bickel, Higgins, Kirby, \& Johnson, 1988; Weiner, 1964, 1969), persistence (Eisenberger, 1992; Seligman \& Maier, 1967) and topography (Midgley, Lea, \& Kirby, 1989; Muenzinger et al., 1929; Stokes \& Balsam, 1991) are all influenced by initial conditions. For example, Stokes and Balsam showed that preselected approximations reinforced early in shaping remain in rats' repertoires even when they are no longer required by the reinforcement contingency. Eisenberger (1992) has demonstrated that, compared with training on easy problems, training on difficult problems results in persistence on impossible ones.

Given that initial conditions influence what we do as well as how long we continue to do it, the main question asked by the present set of experiments was: Can initial conditions determine how differently we continue to do something?

To evaluate the viability of using a previously developed multicomponent observational methodology (Stokes \& Balsam, 1991) in assessing variability in response form, the effects of schedule changes on variation in discretely defined response components and sequences of components were examined in Experiment 1. Because 
most prior work had measured variability along similar or identical response dimensions (e.g., force), Experiment 1 extended the study of response variability to topographically as well as functionally dissimilar behaviors. The question of consistent degree or level of variability was explicitly examined in Experiment 2, which asked if initial conditions continued to affect variability when conditions changed.

\section{EXPERIMENT 1 Effects of Reinforcement Schedules}

To determine how well a component organization analysis captured changes in operant variability predicted on the basis of earlier studies, Experiment 1 incorporated the sequence of schedule changes used by Antonitis (1951) - CRF, extinction, CRF - with the addition of a second extinction session following reacquisition of the operant response. On the basis of Antonitis's results, variability was predicted to decline when the CRF requirement was imposed or reinstated, to further decline during continued CRF, and to increase in extinction.

\section{Method}

\section{Subjects}

The subjects were 4 experimentally naive male Sprague-Dawley albino rats, approximately 12 weeks old at the start of the experiment. They were housed individually with food continuously available in their home cages. After baseline observation, each had $6 \mathrm{~h}$ of free access to water, followed by $48 \mathrm{~h}$ of water deprivation prior to experimental sessions.

\section{Apparatus}

The apparatus consisted of one Lehigh Valley Electronics conditioning chamber ( $23 \mathrm{~cm}$ long, $20.3 \mathrm{~cm}$ wide, and $19.5 \mathrm{~cm}$ high), with clear Plexiglas sides $(0.6 \mathrm{~cm})$ and tops $(0.3 \mathrm{~cm}$ wide) and aluminum front and rear walls. The grid floor was made of stainless steel rods, $0.4 \mathrm{~cm}$ in diameter, spaced $1.1 \mathrm{~cm}$ center to center, and located $4 \mathrm{~cm}$ above the base. The chamber contained a recess $(7.5 \times 5.5 \times 1 \mathrm{~cm})$ in which a dipper presented $0.016 \mathrm{ml}$ of water. The recess was centered on the intelligence panel $1.5 \mathrm{~cm}$ above the base. A metal lever $(2.5 \times 1.8 \times 0.7 \mathrm{~cm})$ with rounded sides was mounted $2.5 \mathrm{~cm}$ above the base and $2.8 \mathrm{~cm}$ to the right of the dipper recess. The lever protruded from a hole $(1.5 \times 3.2 \mathrm{~cm})$. A minimum force of $0.05 \mathrm{~N}$ was needed to close the microswitch. Centered $2.5 \mathrm{~cm}$ above the bar was an unlit light $(1.8 \mathrm{~cm}$ diam), which protruded $1.25 \mathrm{~cm}$ into the chamber. Equipment was housed in a room, approximately $1.5 \times 3 \mathrm{~m}$, illuminated by two $100-\mathrm{W}$ bulbs directed away from the experimental chamber. A Minolta Chroma-Meter CL-100 held 1 in. from the end of the bar at bar height produced a surface illumination of $14.8 \mathrm{~lx}$. A videocamera recorded each subject's behavior. The camera was positioned at approximately bar height, perpendicular to the Plexiglas wall and at the same height as the bar. The camera was approximately $1 \mathrm{~m}$ from the wall; the size of the field was adjusted so that the interior of the chamber filled the picture frame. A microcomputer controlled reinforcer delivery and recorded leverpresses.

\section{Procedure}

Baseline. Nondeprived subjects were placed in the experimental chamber for $30 \mathrm{~min}$ without reinforcer delivery.

Deprived. The subjects were $48 \mathrm{~h}$ water-deprived prior to being placed in the chamber for $30 \mathrm{~min}$, again without reinforcer delivery.
Dipper training. A variable-time 30-sec (VT-30) schedule was used to dipper-train all subjects. This session lasted until 100 reinforcers had been delivered. By the end of training, all subjects reliably and promptly drank from the dipper.

Shaping/CRF. One week after dipper training, each rat was hand-shaped to press the bar by a different experimenter. All experimenters had had experience in shaping rats. Shaping sessions lasted until at least 100 reinforcers had been earned for pressing.

Extinction. One week after shaping, deprived subjects were placed in the experimental chambers for $30 \mathrm{~min}$, during which presses were not followed by reinforcer delivery.

Reacquisition/CRF. Beginning 2 days after extinction, five additional 30-min sessions were conducted in which all presses were reinforced (CRF).

Second extinction. Forty-eight hours after the final CRF session, the rats were placed in the chamber for a 30 -min session during which presses were not followed by reinforcer delivery.

Observations. All sessions were videotaped. Each subject's behavior was sequentially coded by one of 4 independent observers into 47 discrete topographically defined categories as described in the appendix. Twenty percent of analyzed press sequences were selected randomly for code checking by a second observer. One observer was the experimenter. The others were Barnard undergraduates unfamiliar with the predictions being tested. Observer agreement (calculated by dividing total agreements by total agreements plus total disagreements) averaged .87. Reliabilities for individual categories are shown in the appendix.

\section{Measurements}

Response sequences for each subject were analyzed according to transition probabilities from each component to each other component. These probabilities represent the forward flow of behavior: the probability of a response $\left(R_{n}\right)$ conditional on the response preceding it $\left(R_{n-1}\right)$. Figure 1 shows a simplified example of this kind of analysis. The top panel shows forward transition probabilities (multiplied by 100 to give percentages) during 10 consecutive sequences of a hypothetical rat. In every sequence, the same four components appear in the same order. The probability of each component is .25 ; the probability of each transition, 1.0 .

The bottom figure shows forward transition probabilities for another subject who also emits the same components in each sequence, but not in the same order. Each component is followed not by one other component, but by all other components. The probability of each component is still .25 , but now transition or sequential probabilities are less than 1.0 .

To characterize variability, uncertainty measures, derived from information statistics (Attneave, 1959; Brown, 1975; Garner, 1962; Miller \& Frick, 1949), were used. With component uncertainties, we are asking: how likely is it that our subject is engaging in a particular component regardless of the order in which the components occur? If all components are equally likely, uncertainty is maximal. Since our hypothetical subjects did four things equally often, component uncertainties were maximal (2) for both. Departures from equal probabilities among possible outcomes reduce uncertainty. If any component becomes more likely than others, uncertainty is lower. For example, if in each of 10 sequences 1 subject put its head under the bar twice instead of once, "Under" would be more likely than "Dipper," "Over," or "Left," and component uncertainty would drop from 2 to 1.92 .

With sequential uncertainties, we are asking: if the rat is engaging in component $\mathrm{X}$, how likely is it to then engage in component Y? Maximal sequential uncertainty for four components is 6; this is based on 16 pairs occurring equally often. If some pairs occur more often than others, uncertainty declines. For our first subject, sequential uncertainty was 0 : knowing what it had just done, we were never uncertain about what it would do next. Sequential un- 

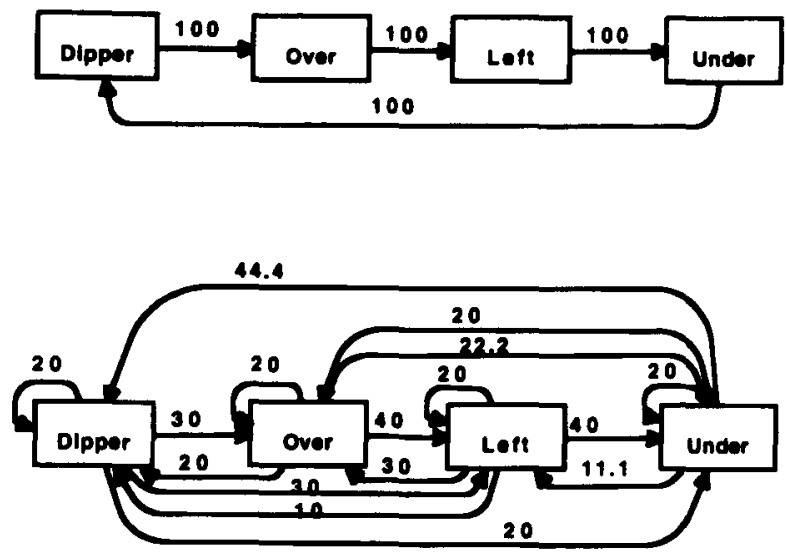

Figure 1. The top and bottom panels show conditional probabilities for 20 reinforced sequences of two hypothetical rats with identical component uncertainties, but different sequential uncertainties. Arrowheads point in the direction of the transition between components. Numbers on arrow shafts represent conditional probabilities of each behavior $\left(R_{n}\right)$ following each other behavior $\left(R_{n-1}\right)$ times 100.

certainty for the second subject was higher (1.8954): we were never completely certain what its next response would be. Notice that equal component uncertainties do not imply equal sequential uncertainties.

The formula

$$
U(R)=-\sum_{n=1}^{n} P\left(R_{n}\right) \log _{2} P\left(R_{n}\right)
$$

- where $U(R)$ is the uncertainty in the set of current responses, $P\left(R_{n}\right)$, the probability that a given response occurred, $N$, the total number of components, and $n$, the individual components that go into $\mathrm{N}$-was used to calculate component uncertainty.

The formula

$$
U(R / R-1)=U(R, R-1)-U(R-1)
$$

-where $U(R / R-1)$ is the uncertainty in the set of current responses $(R)$, given the uncertainty in the set of immediately prior responses $(R-1)$, and $U(R, R-1)$ is the uncertainty in the joint distribution of current and immediately preceding responses-was used to calculate sequential uncertainty.

The above formulas give us absolute or actual uncertainties. An alternative formulation is based on the ratio of the absolute to the maximum uncertainty, and is given by the formula

$$
\text { relative } U=\text { absolute } U / \text { maximum } U \text {, }
$$

where absolute and maximum $U$ s are calculated using the formulas given above. The problem with relative uncertainties in the current set of experiments is finding an appropriate maximum. If the maxima in all phases were equal to everything the species does, we would merely be dividing by a constant. If the maxima were based on everything an individual does in each phase of the experiments, between-phase comparisons would be misleading. This is because manipulations that affect the probabilities of whatever happens in a phase also affect $N$ in that phase. To the extent that this occurs, we would not see the effects of between-phase manipulations. Given that our goal is assessing changes in variability as a result of phase manipulations, the relative measure is inappropriate. Therefore, actual uncertainties were used.

Responding during CRF was analyzed in blocks of 20 reinforced press sequences. Dipper training and extinction were analyzed as complete sessions. Percentage transformations or rescal- ing of absolute frequencies allowed comparisons between the CRF blocks and the dipper and extinction sessions.

\section{Results}

The top and bottom panels of Figure 2 present mean component (What is the probability of "Left"?) and sequential (What is the probability of "Left" being followed by "Under"') uncertainties, respectively, for all subjects during dipper training, the 20 reinforcer blocks when subjects acquired the press (AcqPress: on average, the 41 st to 60 th reinforcers), at the end of acquisition (EndAcq: on average, the $131 \mathrm{st}$ to $150 \mathrm{th}$ reinforcers), at the start (StartReAcq: first 20 reinforcers) and end of reacquisition (EndReac: 801 st to 820th reinforcers), and during both extinction sessions (Ext 1, Ext2).

Does variability change when schedules change? To see if variability shifted when the response requirement was imposed, behavior during dipper training was contrasted with that in the 20-reinforcer block (AcqPress), in which the subjects first earned all reinforcers by press-
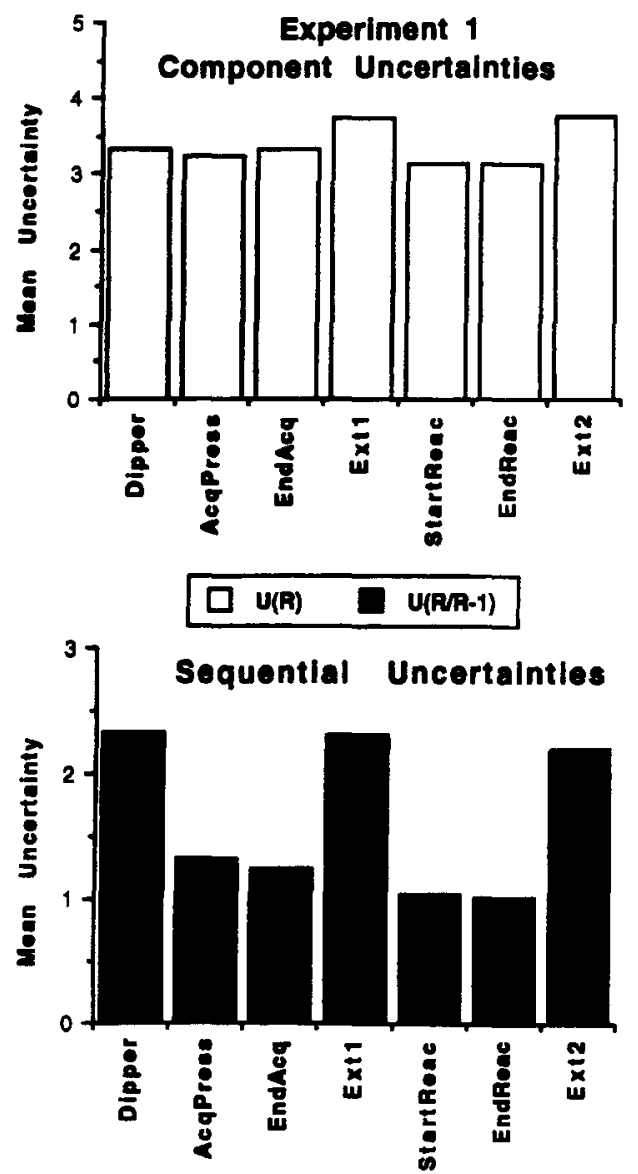

Figure 2. Top panel: Mean component uncertainties. Bottom panel: Mean sequential uncertainties during dipper training (Dipper), when subjects acquired the press (AcqPress), at the end of acquisition (EndAacq), at the start and end of reacquisition (StartReac, EndReac), and during both extinction sessions (Ext1, Ext2) of Experiment 1. All blocks during acquisition and reacquisition include 20 reinforced press sequences. 
Table 1

\begin{tabular}{|c|c|c|c|c|}
\hline Bin & Variable & $b$ & $\begin{array}{c}R 2 \\
\text { Increment }\end{array}$ & $\begin{array}{c}\text { Overall } \\
R 2\end{array}$ \\
\hline \multirow[t]{2}{*}{ AcqPress } & MeanU(R) & $1.008^{*}$ & 1.000 & 1.000 \\
\hline & MeanU(R/R - 1) & $1.153^{*}$ & .988 & .988 \\
\hline \multirow[t]{2}{*}{ EndAcq } & MeanU(R) & $1.037^{*}$ & .992 & .992 \\
\hline & MeanU(R/R - 1) & $1.085^{*}$ & .989 & .989 \\
\hline \multirow[t]{2}{*}{ StartReac } & MeanU(R) & $.981 *$ & .997 & .997 \\
\hline & MeanU(R/R - 1) & $.893^{*}$ & .982 & .982 \\
\hline \multirow[t]{2}{*}{ EndReac } & MeanU(R) & $.974^{*}$ & .989 & .989 \\
\hline & MeanU(R/R-1) & $.869^{*}$ & .980 & .980 \\
\hline
\end{tabular}

Note-MeanU(R) = baseline component uncertainties; MeanU(R/R - 1) $=$ baseline sequential uncertainties. ${ }^{*} p<.01$.

ing. Within-subject $t$ tests showed no shifts in component uncertainty. However, sequential uncertainty declined significantly $[t(3)=5.883, p<.01]$. Sequential $[t(3)=4.246, p<.05]$, but not component, uncertainty also declined between the first extinction and the first 20 reinforcers in reacquisition, when the response requirement was reimposed.

Since subjects were switched from acquisition to extinction and again from reacquisition to extinction, twoway repeated measures analyses of variance (ANOVAs) with condition (CRF or extinction) and repetition (first or second time the switch occurred) as factors were used to compare CRF and extinction. Component $[F(1,3)=$ $11.565, p<.05]$ and sequential uncertainties $[F(1,3)=$ $400.466, p<.01]$ increased between the CRF and extinction phases.

Does variability change when a schedule does not change? The four CRF blocks shown in Figure 2 were compared. One-way repeated measures analyses of variance (ANOVAs) with block as a factor revealed no differences in either component or sequential uncertainties.

Is there a relationship between reinforcer rate and variability? To see if there was a relationship between reinforcer rates and uncertainties at the individual level, Pearson correlations between component uncertainty, sequential uncertainty, and reinforcement rate were run. There was no significant relationship between either uncertainty measure and reinforcer rate for any subject during CRF.

To analyze the effects of reinforcer rate on mean group uncertainties while statistically controlling for individual differences, stepwise regressions were run. Reinforcer rate (per block) and mean component or sequential uncertainty (over the four CRF blocks for each subject) were entered into a regression equation predicting uncertainty in each block. In the stepwise procedure, the independent variable that accounts for the largest proportion of the total variance in the dependent variable is entered first. Other variables, if significant, are then entered in order of their decreasing increments to the total variance. In the four CRF bins analyzed, only baseline uncertainties were significant; reinforcer rate was never entered into the regression equation. For compo- nents, baseline uncertainties accounted for a mean .995 of total variance; for sequences, they accounted for a mean .985. Results of the regression analysis are shown in Table 1.

\section{Discussion}

Experiment 1 replicated the main result reported in earlier studies (e.g., Antonitis, 1951) on the effects of reinforcement schedules: responding was more variable during extinction than during CRF. Contrary to previous findings (Antonitis, 1951; Notterman, 1959; Vogel \& Annau, 1973), variability did not decline during exposure to CRF.

This difference may be due to when variability was measured. Since the main goal of the current study was to examine consistently maintained levels of variability, responding during CRF was measured after the press was acquired. Antonitis's (1951) analysis is typical of most earlier studies. He measured variation in the locus of responding between the first ( 1 st to 25 th reinforcer) session, when subjects had not yet acquired the operant response and the fifth (176th to 225th reinforcer) conditioning session, rather than comparing Sessions 2 through 5, when it appears to have been stable (p. 277).

Variability could have remained constant during CRF because reinforcer rate was relatively stable. This was not the case, however: rates varied from 2 to 14 reinforcers per minute during CRF.

Another reason why variability did not shift during CRF may be that response class size remained constant. This idea is derived from Schoenfeld and Farmer (1970), who pointed out that all behavior can be divided into two classes, a reinforced, or $R$, class, and a nonreinforced, or $\tilde{R}$ class. Figure 3 illustrates this framework. The upper box in the left-hand panel represents differential reinforcement. The $R$ class consists of just those responses which meet the response criteria as defined by the experimenter. The figure shows a small $R$ class - all members of which are inside the boundary of the reinforcement requirement-and a larger $\tilde{R}$ class, in which no response is reinforceable under the current contingency. The lower box represents extinction: there is no longer a boundary. In this view, extinction can be thought of as a change in the boundaries of the $R$ class rather than a change in the frequency of reinforcement. Specifically, the boundary of the $R$ class becomes so small that there is nothing left in it. In the current study, decreasing the size of the $R$ class from some members (all of which were reinforceable) to no members (no response was reinforceable) increased variability.

What happens if we go from a smaller to a larger $R$ class? The right-hand panel of Figure 3 illustrates this kind of change. The top box again represents differential reinforcement of a small $R$ class. It could also be drawn to represent an $R$ class of 0 , either extinction or dipper training. The bottom box represents an increase in the size of the $R$ class. Again, variability changes in the direction opposite to that of the change in class size. This occurred both when the response requirement was intro- 


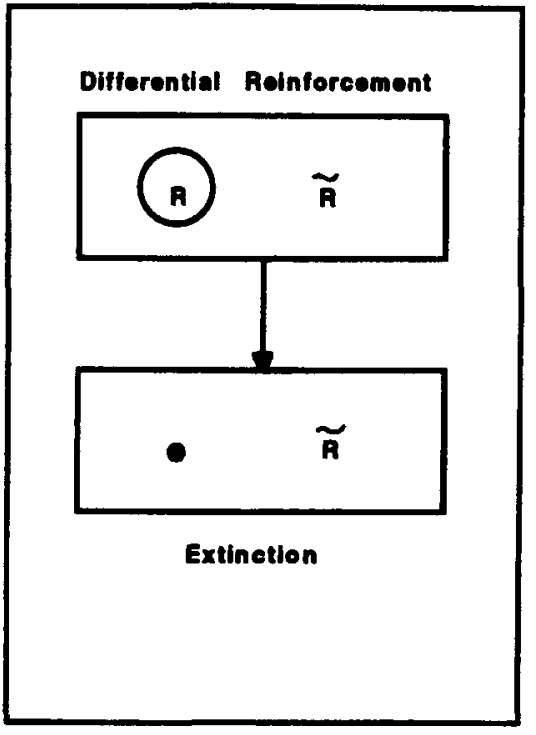

Decrease boundaries of $\mathrm{R}$ class

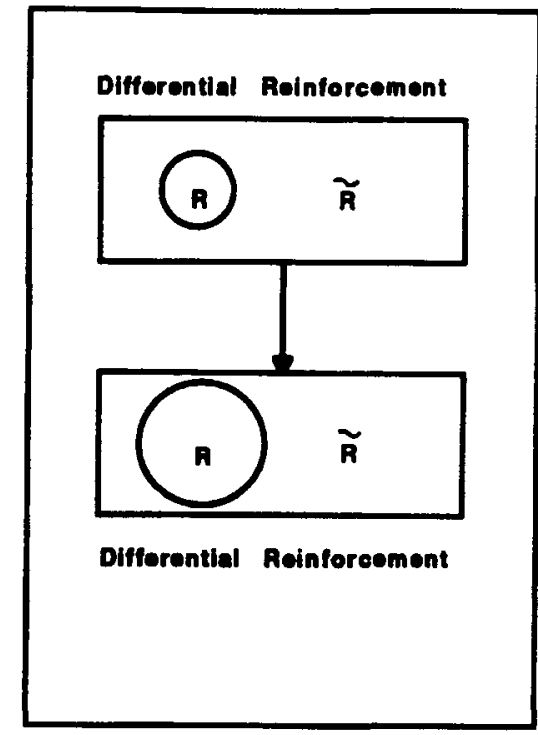

Increase boundaries of $\mathbf{R}$ class

Figure 3. Left panel: Schematic representation of decreasing the boundaries of an $R$ class. The upper box represents differential reinforcement, in which few things are included within the boundary of the $R$ class. The lower box represents extinction; there is no longer a boundary, and nothing remains in the $R$ class. Right panel: Representation of increasing the boundaries of an $R$ class. The boundary of the $R$ class increases in the bottom box; more responses are included in the class.

duced and when it was reinstated after extinction: the size of the reinforced class increased, variability decreased.

Finally, if the size of an $R$ class does not change, there may be no changes in variability. This is what we saw during CRF: once the press was acquired, variability did not change.

There is another way to interpret this consistency. Perhaps during acquisition, subjects were adventitiously reinforced for pressing more or less differently, thus acquiring variability levels which they maintained during CRF. To support this idea requires showing that variability levels are maintained in the presence of a perturbation, for example, a change in the size of the $R$ class during CRF.

\section{EXPERIMENT 2 Effects of Initial Conditions}

Experiment 2, the main goal of which was to examine if initial conditions determine how variably we continue to do something, allowed us to contrast predictions made from $R$ class and acquired variability (or initial condition) hypotheses. According to the first hypothesis, variability moves inversely with class size: changing class size during CRF (by changing response requirements) should change variability. According to the second hypothesis, variability levels conditioned during acquisition should persist during CRF despite changes in requirements.

To examine the effects of initial conditions and of changes in $R$-class size during CRF, subjects were exposed to three topographically defined response require- ments in two different orders. In one group, the requirement was gradually relaxed, thus increasing the size of the $R$ class. In the other, the requirement became successively more restrictive, decreasing the size of the $R$ class.

Figure 4 presents the experimental design for both groups on a continuum from least to most restricted conditions. The most restricted condition was Right; in this condition, reinforcement followed only right-paw presses. The least restricted condition was Any; there was no constraint on press topography. In the middle condition (RtorLft), single-paw presses-right or left-were required. The arrows going from left to right show the order of exposure for the Right-First group; the arrows going from right to left show the order for the Any-First group.

The design also allowed us to examine how constraining specific components would affect response form. If each group's initial condition continued to influence topography (Stokes \& Balsam, 1991), components might differ by group rather than by condition. One possible difference was suggested by Muenzinger et al.'s (1929) report of more "accessory" or unnecessary behaviors (e.g., tapping a latch before pressing) in a group of guinea pigs required to open a latch with the right paw only than in a group free to release the latch in any way.

\section{Method}

\section{Subjects and Apparatus}

The subjects were 10 experimentally naive female SpragueDawley albino rats, approximately 12 weeks old at the start of the experiment. They were housed in pairs with food continuously available in their home cages. After dipper training, water was 


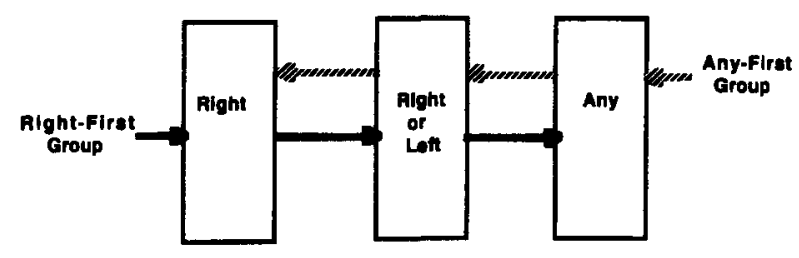

Dasign - Experiment 2

Figure 4. Schematic representation of the design for Experiment 2. The condition with the most restricted response criterion is Right; the least restricted is Any. The solid arrows show the order of exposure to the changes in criterion for the Right-First group; the striped arrows show the order for the Any-First group. Subjects earned 600 reinforcers in each condition.

available on the following cycle. Prior to the start of each cycle of four successive daily experimental sessions, they were $48 \mathrm{~h}$ waterdeprived. At the end of each session, they were given 5 min of access to water. After the fourth session, the subjects were given $24 \mathrm{~h}$ of free access to water before the cycle began again.

\section{Procedure}

Baseline, deprived, dipper training. As in Experiment 1, the subjects were first exposed to 30-min baseline (nondeprived, nonreinforced) and deprived ( $48 \mathrm{~h}$ deprived, nonreinforced) observation sessions. These were followed by a $1-h$ dipper training session ( $48 \mathrm{~h}$ deprived, VT 30 -sec schedule).

Shaping. After dipper training, the subjects were assigned randomly to either Right or Any-First groups $(N=5)$ and shaped in their respective initial conditions (Right or Any) until they had earned 200 reinforcers. In the Right-First group, reinforcement was specified initially for orienting toward the bar and then for any kind of bar contact. Once bar contact was established, reinforcement followed any kind of press. Finally, only press sequences in which the last paw-bar contact was made with the right paw were rewarded. During shaping, reinforcers were delivered by an observer who watched the rats on a video monitor. All subjects met the shaping criterion in one session.

In the Any-First group, reinforcement was specified first for orienting toward the bar, then for bar contact, and finally for any kind of press. Two subjects in the Any-First group (Rats E1 and E2) needed two sessions to acquire the press and earn the requisite 200 reinforcers. All other subjects met the shaping criterion in one session. Mean duration of shaping sessions was $55 \mathrm{~min}$. The initial contingencies continued for an additional 600 trials, which occurred over two subsequent sessions for all subjects. Mean length of these sessions was $32 \mathrm{~min}$.

Changing response requirements. After earning 600 reinforcers in two CRF sessions under their initial requirements, the subjects were switched to the Right or Left condition. They were again required to earn 600 reinforcers, and all rats did so in two sessions. For their final 600 reinforcers, the subjects in the Any-First group were switched to the Right condition and those in the Right-First group were switched to the Any condition. One rat in the Any-First group (Rat D2) had to be reshaped to press with its right paw before earning its 600 reinforcers in CRF in the Right-only condition. Mean session duration under the changed contingencies was $31 \mathrm{~min}$. An observer watched the rats on a video monitor and delivered reinforcers in Right and in Right or Left conditions. In the Any condition, presses were automatically followed by reinforcer delivery.

Extinction. Following completion of CRF, all subjects were placed in the experimental chamber for two $1-h$ extinction sessions, during which reinforcers were not delivered.
Observations. All sessions were videotaped. Three independent observers coded the baseline, deprived, dipper, shaping, and extinction sessions in their entirety, as well as the first 50 and last 100 reinforced trials in each CRF phase.

The coding scheme was amended to allow observers to make finer discriminations. Of 23 components added to the code, 11 were in the bar-directed category. Four of these were variations of paw behavior; 5 were of head behavior. The appendix includes the enlarged code. Interobserver agreement (shown for each component in the appendix) averaged .95 in this experiment.

\section{Results}

Individual component and sequential data (not presented) showed that 3 subjects in the Any-First group did not contact any change in contingency until they got to the Right condition. These subjects pressed predominantly with the left paw, a behavior which met the response criteria both in the Any and in the Right or Left conditions. Thus, the size of their response class did not change until exposure to the Right-Only condition. Since one purpose of the experiment was to examine differences in variability following from differences in $R$-class size, the groups were compared during the Right and Any conditions. Since the strongest test of the manipulation would take place at the end of training, the last 50 reinforced press sequences in these conditions were examined.

Does variability change when response criteria change? Two-way repeated measures ANOVAs with group (Right or Any-First) and condition (Right or Any) were used to answer this question. There was only one significant result, a main effect of group on sequential uncertainty $[F(1,8)=5.474, p<.05]$. As shown in Figure 5, which presents mean sequential uncertainties collapsed over both conditions, Right-First rats were more variable than AnyFirst rats at the ends of the Right and Any conditions.

Did the two groups differ prior to or after conditioning? Two-way repeated measures ANOVAs, with group (Right and Any-First) and condition (dipper, Ext1, and Ext2), were used to answer this question. Figure 6 presents mean component and sequential uncertainties collapsed over groups for dipper training and the two extinction sessions (Ext1, Ext2). There were no between-group dif-

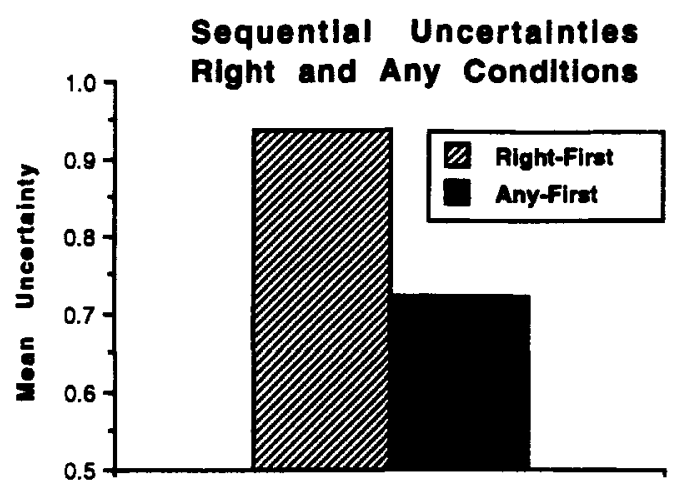

Figure 5. Mean sequential uncertainties collapsed over the last 50 reinforcers earned in Right and Any conditions for each group separately. 


\section{Uncertainties \\ Pre- and Post-conditioning}

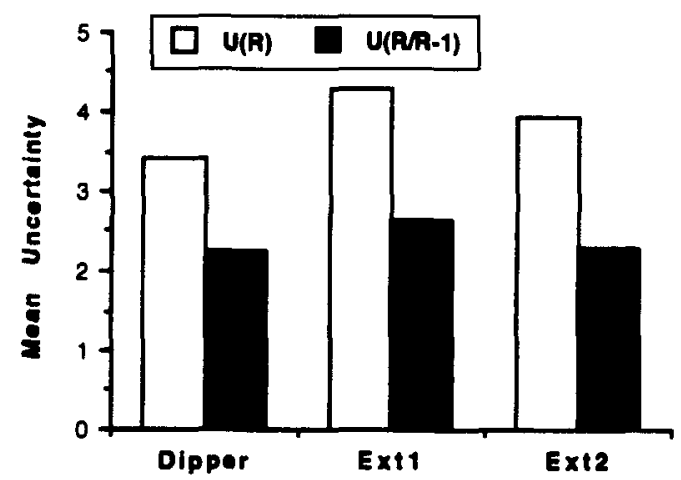

Figure 6. Mean component and sequential uncertainties collapsed over groups during dipper training (Dipper) and the first (Ext1) and second (Ext2) extinction sessions.

ferences. However, there were main effects of condition on both component $[F(2,7)=14.653, p<.01]$ and sequential uncertainty $[F(2,7)=7.448, p<.05]$. Planned contrasts showed that component uncertainty differed between each pair of conditions. It was higher during Extl than during dipper training $[F(2,8)=16.545, p<$ $.001]$ or Ext2 $[F(2,8)=4.455, p<.05]$. It was lower during dipper training than during the second extinction session $[F(2,8)=7.933, p<.05]$.

Sequential uncertainty was also higher in the first extinction session than in either dipper training $[F(2,8)=$ $8.839, p<.01]$ or the second extinction session $[F(2,8)=$ $4.484, p<.05]$. However, there was no difference between dipper training and Ext2. With repeated exposure to extinction, subjects recovered preconditioning levels of sequential variability, and this did not differ by group.

Is there a relationship between reinforcer rate and variability when contingencies are successively changed during $C R F$ ? To see if there was a relationship between reinforcer rate and uncertainties at the level of the individual subject, Pearson correlations between reinforcer rate and component and sequential uncertainties for each block were run separately for each subject. To have enough points for the correlational analyses, behavior was sampled at the starts (first 50 reinforcers) and the ends (last 50 reinforcers) of each condition. Correlations and significance levels for all subjects are shown in Table 2.

In the Right-First group, there was no relationship between reinforcer rate and uncertainties for 2 rats (R1, R2); for 2 others (R3, R4), both component and sequential uncertainties were significantly correlated with reinforcer rate. For the last rat (R5), only sequential uncertainty was related to rate of reinforcement. In the Any-First group, there was no relationship between rate and uncertainty in 1 subject (A3); for another (A1), both relationships were significant. For the remaining 3 rats, there were correlations between rate and either component (A4) or sequential (A2, A5) uncertainty. While these patterns of results appear to reflect individual differences more than differences in reinforcer rates, all correlations were in the same direction (negative).

To examine the effects of reinforcer rate on mean group uncertainties while controlling for individual differences, stepwise regressions using rate (for each block) and mean uncertainties (over all blocks for each subject) to predict uncertainty were used. These results are presented in Table 3. Over all blocks in the RightFirst group, mean uncertainties contributed a mean .988 to total variance for component and .886 to sequential uncertainty. Rate was a significant predictor of component uncertainty only once, and that was in the first 50 trials of the Right or Left condition (RtorLftl). In the Any-First group, baseline uncertainties contributed a mean .983 to component and .926 to sequential uncertainty. Reinforcer rate was never a significant predictor of uncertainty.

How does reinforcement history affect topography? To examine changes in paw topography, frequencies were collapsed in three categories. The first two were directly related to the criteria changes. Left, Both, and Grasp were combined, since they were all excluded by the Right requirement; Right was a separate category. The third (Paw Variants) consisted of accessory behaviors (Muenzinger et al., 1929), that is, responses unnecessary to pressing. Paw Variants are indicted in the appendix by asterisks. Two examples are sliding the paw over the surface of the bar (Slide) and waving it in the air next to the bar (Flail).

Figure 7 shows these frequencies for both groups. Twoway repeated measures ANOVAs with group and condition as factors showed that, overall, more total paw responses $[F(1,8)=15.461, p<.01]$ and more Paw Variants $[F(1,8)=11.98, p<.01]$ were observed in the RightFirst group. For both groups, more total paw $[F(1,8)=$ $7.775, p<.05]$ and more Paw Variants $[F(1,8)=6.718$, $p<.05]$ occurred in the Right condition. Total paw behavior [group $\times$ condition, $F(2,7)=11.405, p<.01$ ] declined between the Right and Any conditions in the Right-First group $[t(4)=5.501, p<.01]$.

Table 2

Results of Pearson Correlation Analyses Between Reinforcer Rates and Uncertainties in Experiment 2

\begin{tabular}{cccc}
\hline \multirow{2}{*}{ Group } & & \multicolumn{2}{c}{ Correlation Reinforcer Rate } \\
\cline { 2 - 4 } Right-First & Subject & with $U(R)$ & with $U(R / R-1)$ \\
& R1 & -.481 & -.742 \\
& R2 & -.700 & -.752 \\
& R3 & $-.811 \dagger$ & $-.852^{\dagger}$ \\
& R4 & $-.927^{*}$ & $-.949^{*}$ \\
Any-First & R5 & -.807 & $-.865 \dagger$ \\
& A1 & $-.879 \dagger$ & $-.898^{*}$ \\
& A2 & -.789 & $-.923^{*}$ \\
& A3 & -.805 & -.709 \\
& A4 & $-.830 \dagger$ & -.730 \\
& A5 & -.717 & $-.841 \dagger$ \\
\hline
\end{tabular}

Note- $U(R)=$ component uncertainty $U(R / R-1)=$ sequential uncertainty. ${ }^{*} p<.01 . \quad \dagger p<.05$. 
Table 3

Results of Stepwise Regression Analyses Predicting Component and Sequential Uncertainties

\begin{tabular}{|c|c|c|c|c|}
\hline Bin & Variable & $b$ & $\begin{array}{c}R 2 \\
\text { increment }\end{array}$ & $\begin{array}{c}\text { Overal } \\
R 2 \\
\end{array}$ \\
\hline \multicolumn{5}{|c|}{ Right-First Group } \\
\hline \multirow[t]{2}{*}{ RightS } & $\operatorname{Mean} U(R)$ & $1.126^{*}$ & .998 & .998 \\
\hline & $\operatorname{Mean} U(R / R-1)$ & $1.428^{*}$ & .958 & .958 \\
\hline \multirow[t]{2}{*}{ RightE } & $\operatorname{Mean} U(R)$ & $.889^{*}$ & .980 & .980 \\
\hline & $\operatorname{Mean} U(R / R-1)$ & $.695^{*}$ & .863 & .863 \\
\hline \multirow[t]{3}{*}{ RtorLftS } & $\operatorname{Mean} U(R)$ & $1.411^{*}$ & .987 & .987 \\
\hline & Rate & $-0.077+$ & .012 & .999 \\
\hline & $\operatorname{Mean} U(R / R-1)$ & $1.145^{*}$ & .856 & .856 \\
\hline \multirow[t]{2}{*}{ RtorLftE } & $\operatorname{Mean} U(R)$ & $.917^{*}$ & .996 & .996 \\
\hline & $\operatorname{Mean} U(R / R-1)$ & $.505 \dagger$ & .832 & .832 \\
\hline \multirow[t]{2}{*}{ AnyS } & $\operatorname{Mean} U(R)$ & $1.018^{*}$ & .986 & .986 \\
\hline & $\operatorname{Mean} U(R / R-1)$ & $.829^{*}$ & .982 & .982 \\
\hline \multirow[t]{2}{*}{ AnyE } & $\operatorname{Mean} U(R)$ & $1.017^{*}$ & .981 & .981 \\
\hline & $\operatorname{Mean} U(R / R-1)$ & $.737 \dagger$ & .824 & .824 \\
\hline \multicolumn{5}{|c|}{ Any-First Group } \\
\hline \multirow[t]{2}{*}{ AnyS } & $\operatorname{Mean} U(R)$ & $1.095^{*}$ & .992 & .992 \\
\hline & $\operatorname{Mean} U(R / R-1)$ & $1.353^{*}$ & .942 & .942 \\
\hline \multirow[t]{2}{*}{ AnyE } & $\operatorname{Mean} U(R)$ & $.950^{*}$ & .980 & .980 \\
\hline & $\operatorname{Mean} U(R / R-1)$ & $.739^{*}$ & .969 & .969 \\
\hline \multirow[t]{2}{*}{ RtorLftS } & $\operatorname{Mean} U(R)$ & $1.041^{*}$ & .991 & .991 \\
\hline & $\operatorname{Mean} U(R / R-1)$ & $1.172^{*}$ & .958 & .958 \\
\hline \multirow[t]{2}{*}{ RtorLftE } & $\operatorname{Mean} U(R)$ & $.920^{*}$ & .974 & .974 \\
\hline & $\operatorname{Mean} U(R / R-1)$ & $.715^{*}$ & .924 & .924 \\
\hline \multirow[t]{2}{*}{ RightS } & $\operatorname{Mean} U(R)$ & $1.109^{*}$ & .982 & .982 \\
\hline & $\operatorname{Mean} U(R / R-1)$ & $1.483^{*}$ & .860 & .860 \\
\hline \multirow[t]{2}{*}{ RightE } & $\operatorname{Mean} U(R)$ & $1.038^{*}$ & .979 & .979 \\
\hline & Mean $U(R / R-1)$ & $1.135^{*}$ & .902 & .902 \\
\hline
\end{tabular}

Note-Mean $U(R)=$ baseline component uncertainties; $\operatorname{Mean} U(R / R-1)$ $=$ mean baseline sequential uncertainties; $\mathrm{S}=$ first 50 reinforcers at start of each condition; $\mathrm{E}=$ last 50 reinforcers at end of each condition. ${ }^{*} p<.01 . \quad \dagger p<.05$.

\section{Discussion}

\section{Variability}

In Experiment 2, initial conditions influenced variability late in CRF, but not during extinction. Since the size of the $R$ class changed during CRF, variability cannot be simply an inverse function of $R$ class size. If it were, between-condition differences would have been seen during CRF in both groups. This was not the case. Rather, the Right-First group showed a consistently higher level of sequential variability than the Any-First group in both Right and Any conditions, suggesting that, during shaping, subjects acquired not only a response repertoire but also a variability level. That is, they learned what to do and how differently to do it during CRF.

To say a variability level is acquired means it becomes conditioned. How could this happen? Perhaps, in addition to the explicit topographic criteria, there were also implicit variability criteria. Explicit variability criteria make reinforcement dependent on a current response's being different from a prior response or responses. The greater the difference required, the greater the variability (e.g., Machado, 1992). Implicit variability criteria could arise if sequential patterns which meet initial topographic requirements are adventitiously reinforced. As a result of such implicit variability criteria, the setting of an en- dogenous variability generator (Neuringer, 1988) may be conditioned. Alternatively, a set of response-produced sensations related to, say, number of different responses made may become conditioned reinforcers (for a related argument, see Eisenberger, 1992, on learned industriousness). In this case, subjects continue to emit response patterns that generate the conditioned reinforcers.

Support for the idea that a level is acquired comes from the fact that the two groups did not differ prior to training. After training, sequential training was greater for the Right-First group than for the Any-First group. The question then becomes, why would Right-First rats experience a more stringent implicit variability criterion in training? One possibility is that shaping right paw presses involved more steps (i.e., more different approximations) than did shaping with no topographic requirement. Relative to Any-First subjects, Right-First subjects may have initially been reinforced more often for making a current response different from a previous one. A second possibility is that shaping right paw presses was a less structured or less completely specified problem. Joyce and Chase (1990) showed that greater variability resulted from incompletely specified instructions than from completely specified ones. A third putative reason why Right-First rats would make more different responses early in training involves reinforcer delivery. In the Any condition, reinforcers were provided automatically by the equipment. In the Right condition, they were delivered by the experimenter. Thus, longer latencies as well as less consistency in the contingency, either of which could generate greater variability, may have occurred in the Right condition.

Notice that while fewer steps may have been involved when Any-First rats learned to press with the right paw only (e.g., pressing was already acquired), switching to experimenter delivery and to a less completely specified problem did not increase variability in Any-First rats later in training.

\section{Paw/Accessory Behaviors}

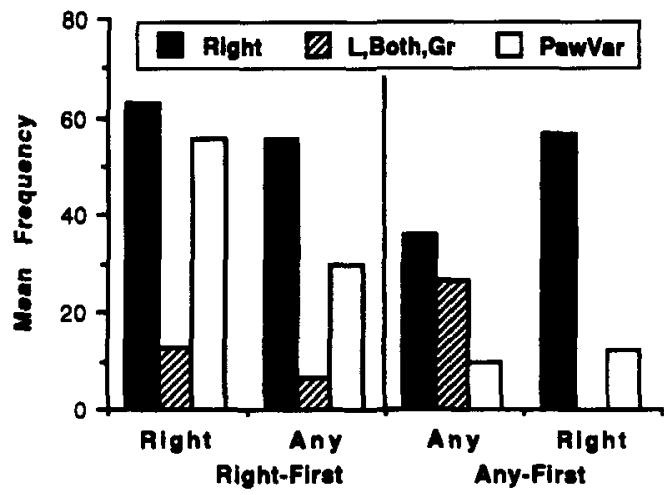

Figure 7. Mean frequencies for Right, LeftBothGrasp, Paw Variants and Head components at the end of the Right and Any conditions for the Right-First (left panel) and Any-First (right panel) groups. 
It could be argued that variability depends on the number of reinforced variants (of the target response) that remain in subjects' repertoires (Midgley et al., 1989; Stokes \& Balsam, 1991). While higher frequencies of total paw responses and of paw variants were observed in the RightFirst group during both CRF conditions, total paw responding declined between Right and Any conditions for this group. Thus, repertoire size by itself appears inadequate as an explanation for maintained levels of variability.

\section{Topography}

Initial conditions continued to affect response form in both groups. Paralleling Muenzinger et al.'s (1929) results, more accessory behaviors (paw variants) were observed in the Right-First group both early and late in training. When the Any-First group was required to press with the right paw only, variations in paw topography did not increase significantly.

\section{GENERAL DISCUSSION}

\section{Findings}

The current study investigated the effects of reinforcement schedules and reinforcement history, specifically initial conditions, on behavioral variability. The results of changing reinforcement schedules were quite systematic. When schedules were switched from dipper training or extinction to CRF, uncertainties decreased. A change in the opposite direction (from CRF to extinction) produced the opposite result: uncertainties increased. With no change in schedule (CRF), there were no shifts in uncertainties. The results of changing response criteria within CRF were also consistent. In Experiment 2, neither relaxing nor restricting response requirements changed uncertainties: within-group variability at the end of both Any and Right CRF phases was the same. Between-group differences appear to be based on initial conditions: greater sequential variability was seen in the Right-First group, which had been trained with the more restrictive response criterion.

\section{Hypotheses}

\section{Variability as a Function of Reinforcer Rate}

The hypothesis that changes in reinforcer rate cause shifts in variability remains plausible in cases of changed schedules, between, say, CRF and extinction. However, within a schedule, rates are not reliably related to variability. There is independent evidence of this within intermittent schedules of reinforcement. While Eckerman and Lanson (1969) showed that variation in response location increased during intermittent schedules relative to CRF, it did not shift systematically with intermittent schedule values. Rather, as in the present study, variation for each subject was idiosyncratic.

Within CRF, rate was not related to uncertainties at either individual or group levels in Experiment 1. While significant correlations between rate and uncertainties during CRF were observed on the level of the individual subject in Experiment 2, there were no consistent withinor between-group patterns.

\section{Variability as a Function of $\boldsymbol{R}$ Class Size}

The $R$-class hypothesis supposes that variability is an inverse function of the size of a reinforced or $R$ class. If dipper training and extinction involve $R$ classes with 0 members and reinforcement involves a class with $N$ members, the model can account for changes in variability when schedules change. If a response requirement remains the same during CRF, the $R$ class remains the same. This can account for the unchanged variability during CRF in Experiment 1 . If a change in response requirement increases or decreases the size of the $R$ class, then variability should change (in the opposite direction). This did not occur in Experiment 2: response requirements changed, the size of the $R$ class increased or decreased, but variability was maintained at the level established during the initial requirement.

\section{Variability as a Function of an Acquired Level}

According to the acquired-variability-level hypothesis, task acquisition involves both a response repertoire and a variability level, which subjects maintain despite perturbations caused by changed response requirements. The level is conditioned via either response- or stimulusreinforcer associations. In the first case, subjects learn how differently to make a response; in the second, proprioceptive sensations produced by low or high variation in responding become conditioned reinforcers.

Empirical support for this idea was provided by the results of Experiment 2. Subjects contacted and remained in contact with changes in response requirements, yet uncertainties were maintained at levels of their initial conditions. Support for the idea that a variability level is acquired during training was also obtained: while the groups differed in sequential uncertainties at the ends of both Right and Any conditions, there were no betweengroup differences prior to training. The fact that there were no differences during extinction also supports the idea that variability levels during CRF were conditioned to reinforcement. Without reinforcement, variability returned to preconditioning levels.

\section{Implications and Future Directions}

The main implication of the acquired-variability-level account for the development of consistent individual differences in variability is straightforward. Like rate (Weiner, 1964, 1969), persistence (Eisenberger, Masterson, \& McDermitt, 1982), and form (Stokes \& Balsam, 1991), response variability is a function of an individual's early learning history.

Implicit variability criteria appear to be crucial in that learning history. Thus, an important area for investigation is how such criteria are established. One suggestion comes from Experiment 2. Number of training steps influences early, adventitiously reinforced levels of variation. The 
more steps, the more variation. A second suggestion comes from Joyce and Chase's (1990) comparison of completely and incompletely specified instructions. Incomplete instructions generate greater initial levels of variability than do complete instructions. If steps and specificity interact, prediction is more difficult. For example, if instructions are completely specified, number of steps may not matter.

Finally, questions about step size and criterion specificity need to be investigated with human subjects. Understanding how implicit variability criteria are embedded in training has practical importance for education. In many problem-solving areas, including arithmetic (Carpenter \& Moser, 1982; Fuson, 1982; Seigler, 1994) and causal attribution (Kuhn \& Phelps, 1982; Schauble, 1990), the range or number of strategies used by individuals does not diminish when more efficient strategies are learned. Rather, the distribution shifts. The current work indicates that these kinds of individual differences are - to a large extent-learned, and suggests ways to study what in the learning determines the level.

\section{REFERENCES}

Alleman, H. D., \& Zeiler, M. D. (1974). Patterning with fixed-time schedules of response-independent reinforcement. Journal of the Experimental Analysis of Behavior, 22, 135-141.

ANTONITIS, J. J. (1951). Response variability in the white rat during conditioning, extinction and reconditioning. Journal of Experimental Psychology, 42, 273-281.

ATTNEAVE, F. (1959). Applications of information theory to psychology: A summary of basic concepts. New York: Holt, Rinehart \& Winston.

Bickel, W. K., Higgins, S. T., KirbY, K., \& Johnson, L. M. (1988). An inverse relationship between baseline fixed-interval response rate and the effects of a tandem response requirement. Journal of the Experimental Analysis of Behavior, 50, 211-218.

BLOUGH, D. S. (1966). The reinforcement of least-frequent interresponse times. Journal of the Experimental Analysis of Behavior, 9 , $581-591$.

Brown, M. B. (1975). The asymptotic standard errors of some estimates of uncertainty in the two-way contingency table. Psychometrika, 40, 291-296.

Bryant, D., \& Church, R. M. (1974). The determinants of random choice. Animal Learning \& Behavior, 2, 245-248.

Carpenter, T. P., \& Moser, J. M. (1982). The development of addition and subtraction problem-solving skills. In T. P. Carpenter, J. M. Moser, \& T. A. Romberg (Eds.), Addition and subtraction: A cognitive perspective (pp. 9-24). Hillsdale, NJ: Erlbaum.

Christensen, P. R., Guilford, J. P., \& Wilson, R. C. (1957). Relations of creative responses to working time and instructions. Journal of Experimental Psychology, 53, 82-88.

ECKERMAN, D. A., \& LANSON, R. N. (1969). Variability of response location for pigeons responding under continuous reinforcement, intermittent reinforcement, and extinction. Journal of the Experimental Analysis of Behavior, 12, 73-80.

EISENBERGER, R. (1992). Learned industriousness. Psychological Review, 99, 248-267.

Eisenberger, R., Masterson, F. A., \& MCDermitt, M. (1982). Effects of task variety on generalized effort. Journal of Educational Psychology, 74, 499-505.

Fuson, K. C. (1982). An analysis of the counting-on solution procedure in addition. In T. P. Carpenter, J. M. Moser, \& T. A. Romberg
(Eds.), Addition and subtraction: A cognitive perspective (pp. 6781). Hillsdale, NJ: Erlbaum.

GARNER, W. R. (1962). Uncertainty and structure as psychological concepts. New York: Wiley.

Guthrie, E. R., \& Horton, G. P. (1946). Cats in a puzzle box. New York: Rinehart

HeRRnStein, R. J. (1961). Stereotypy and intermittent reinforcement. Science, 133, 2067-2069.

Holman, J., Goetz, E., \& BaER, D. M. (1977). The training of creativity as an operant and an examination of its generalization characteristics. In B. C. Etzel, J. M. LeBlanc, \& D. M. Baer (Eds.), New developments in behavioral research: Theory, method and application (pp. 441-471). New York: Wiley.

JOYCE, J. H., \& CHASE, P. N. (1990). Effects of response variability on the sensitivity of rule-governed behavior. Journal of the Experimental Analysis of Behavior, 54, 251-262.

KuHN, D., \& PhelPS, E. (1982). The development of problem-solving strategies. In H. W. Reese (Ed.), Advances in child development and behavior (Vol. 17, pp. 2-44). New York: Academic Press.

LACHTER, G. D., \& COREY, J. R. (1982). Variability of the duration of an operant. Behavior Analysis Letters, 2, 97-102.

MACHADO, A. (1989). Operant conditioning of variability using a percentile reinforcement schedule. Journal of the Experimental Analysis of Behavior, 52, 155-166.

MACHADO, A. (1992). Behavioral variability and frequency-dependent selection. Journal of the Experimental Analysis of Behavior, 58, 241263.

Maltzman, I. (1960). On the training of originality. Psychological Review, 67, 229-242.

MidGLEY, M., LEA, S. E. G., \& KIRBY, R. M. (1989). Algorithmic shaping and misbehavior in the acquisition of token deposit by rats. Journal of the Experimental Analysis of Behavior, 52, 27-40.

Miller, G. A., \& FrICK, F. C. (1949). Statistical behavioristics and sequences of responses. Psychological Review, 56, 311-324.

MoRRIs, C. J. (1987). The operant conditioning of response variability: Free-operant versus discrete-response procedures. Journal of the Experimental Analysis of Behavior, 47, 273-277.

Muenzinger, K. F., KoerNer, L., \& IREY, E. (1929). Variability of an habitual movement in guinea pigs. Journal of Comparative Psychology, 9, 425-436.

Neuringer, A. (1986). Can people behave 'randomly'? The role of feedback. Journal of Experimental Psychology: General, 115, 62. 75.

NEURINGER, A. (1991). Operant variability and repetition as functions of interresponse time. Journal of Experimental Psychology: General, 115, 429-452.

Neuringer, A. (1993). Reinforced variation and selection. Animal Learning \& Behavior, 21, 83-91.

Notterman, J. M. (1959). Force emission during bar pressing. Journal of Experimental Psychology, 58, 341-347.

PAGE, S., \& NeURINGER, A. (1985). Variability is an operant. Journal of Experimental Psychology: Animal Behavior Processes, 11, 429-452.

Pyror, E. W., HAAG, R., \& O'ReillLy, J. (1969). The creative porpoise: Training for novel behavior. Journal of the Experimental Analysis of Behavior, 12, 653-661.

RoYCE, J. (1898). The psychology of invention. Psychological Review, 5, 113-144.

Schauble, L. (1990). Belief revision in children: The role of prior knowledge and strategies for generating evidence. Journal of Experimental Child Psychology, 49, 31-57.

SCHOENFELD, W. N., \& FARMER, J. (1970). Reinforcement schedules and the "behavior stream." In W. N. Schoenfeld (Ed.), The theory of reinforcement schedules (pp. 215-245). New York: Appleton-CenturyCrofts.

SChoENfeld, W. N., Harris, A. H., \& Farmer, J. (1966). Conditioning response variability. Psychological Reports, 19, 551-557.

ScHWARTZ, B. (1982a). Failure to produce response variability with reinforcement. Journal of the Experimental Analysis of Behavior, 37, 171-181. 
SCHWARTZ. B. (1982b). Reinforcement-induced behavioral stereotypy: How not to teach people to discover rules. Journal of Experimental Psichologi: General. 111. 23-59

SEIGLER, R. S. (1994). Cognitive variability: A key to understanding cognitive development. Currene Directions in Psichological Science, 3, 1-5.

SeIgler, R. S., \& Jenkins, E. (1989). How children discoler new strategies. Hillsdale. NJ: Erlbaum.

Seligman, M. E. P., \& Maier. S. (1967). Failure to escape from traumatic shock. Journal of Experimental Psichology, 74, 1-9.

STOKES, P. D., \& BALSAM, P. D. (1991). Effects of reinforcing preselected approximations on the topography of the rat's bar press. Journal of the Experimental Analisis of Behavior, 55, 213-231
Tatham. T. A., Wanchisen, B. A.. \& Hineline, P. N. (1993). Effects of fixed and variable ratios on human behavioral variability. Journal of the Experimental Analusis of Behavior, 59, 349-359.

Vogel., R., \& AnNau, Z. (1973). An operant discrimination task allowing variability of reinforced response patterning. Journal of the Experimental Analssis of Behavior, 20, 1-6

WriNER, H. (1964). Conditioning history and human fixed-interval performance. Journal of the Experimental Analysis of Behavior, 7. 383-385.

WEINER, H. (1969). Controlling human fixed-interval performance. Journal of the Experimental Analysis of Behavior, 12, 349-373.

WoNG, P. T. P. (1977). Partial reinforcement and the learning of a strategy in the rat. American Journal of Psychology, 90, 663-674.

\section{APPENDIX \\ Definition of Behavioral Categories and Interobserver Reliabilities (Reliabilities: Experiment 1/Experiment 2)}

\section{A. Contact Components}

\begin{tabular}{|c|c|}
\hline $\mathbf{R}$ & $\begin{array}{l}\text { RightPaw } \\
(.85 / .99)\end{array}$ \\
\hline $\mathbf{R u}$ & $\begin{array}{l}\text { RightUnder* } \\
(-/ 1.0)\end{array}$ \\
\hline $\mathbf{L}$ & $\begin{array}{l}\text { LeftPaw } \\
(.96 / .96)\end{array}$ \\
\hline Lu & LeftUnder* \\
\hline B & $\begin{array}{l}\text { BothPaws } \\
(-/ .89)\end{array}$ \\
\hline $\mathrm{Bu}$ & BothUnder*† \\
\hline $\mathrm{Gr}$ & $\begin{array}{l}\text { Grasp } \\
(1.0 / .96)\end{array}$ \\
\hline GRU & $\begin{array}{l}\text { GraspRightUnder } \\
(-/ 1.0)^{* \dagger}\end{array}$ \\
\hline
\end{tabular}

Hd

Sl

$$
(-/ 1.0)
$$

S1 Slide*

$(-1.95)$

H Hole

$(.66 / .99)$

N Nose

$(-1.93)$

C Chin

$$
(1.0 / .87)
$$

CS Chinslide $\uparrow$

$\mathrm{Ck} \quad$ Cheek $\dagger$

CKS $\quad \stackrel{(-/ 1.0)}{\text { CheekSlide } \dagger}$

M Mouth

$(1.0 / .96)$

$\mathrm{Bi} \quad$ Bite

$(.66 / .86)$

Bg Bang

T (-/1.0)

T Torso

TA Tail

$\mathrm{X} \quad(-/ 1.0)$

$(1.0 / 1.0)$

\section{Bar-Directed Components}

Right paw contacting top of bar. Note: Contact is scored when space cannot be seen between body and bar surface.

Right paw contacting underside of bar.

Left paw contacting top of bar.

Left paw contacting underside of bar.

Both paws contacting top of bar.

Both paws contacting underside of bar.

Bar contact with both paws: one on top surface; one contacting underside.

Reverse of grasp: Left on top, Right on bottom.

Keeping paw in contact with bar while putting head in dipper, usually with straight rather than bent limb.

Glide paw over surface of bar.

Snout in contact with hole at back of bar.

Contact bar with tip of snout.

Any head contact below the mouth.

Slide chin over surface of bar.

Contact bar with cheek.

Slide cheek over surface of bar.

Any mouth contact with bar, excluding Bite.

Contact bar by grasping between teeth.

Contact bar with top of head.

Contact bar with body part other than head, paws, or tail.

Contact bar with tail.

Any depression of bar strong enough to activate microswitch. 
APPENDIX (Continued)

B. Orient Components

Bre BarRear

$(.81 / .73)$

$\begin{array}{ll}\text { BDre } & \text { BarDipperRear } \dagger \\ \text { BLift } & \text { BarLift } \dagger \\ & (-/ .91) \\ \text { Ob } & \text { OrientBar } \dagger \\ & (-1.91) \\ \text { O } & \text { Over }\end{array}$

$(-1.99)$

U Under

$(.88 / .99)$

Bw Bow

$(-1.81)$

Fl Flail* $\dagger$

(一.67)

Tw Twist ${ }^{\dagger}$

$(-/ 1.0)$

$\begin{array}{ll}\text { D } & \begin{array}{l}\text { Dipper } \\ (.97 / 1.0)\end{array} \\ \text { Db } & \begin{array}{l}\text { DipperBoth } \\ (1.0 /-)\end{array} \\ \text { Dr } & \begin{array}{l}\text { DipperRight } \\ (1.0 /-)\end{array} \\ \text { Dl } & \begin{array}{l}\text { DipperLeft } \\ (.87 /-)\end{array} \\ \text { Dre } & \begin{array}{l}\text { DipperRear } \\ (1.0 / 1.0)\end{array} \\ \text { DBre } & \text { DipperBarRear } \dagger \\ & (-11.0) \\ \text { DLift } & \text { DipperLift }\end{array}$

DLift DipperLift $\dagger$

Dn DipperNod

BD BiteDipper

$(-/ 1.0)$

MD MouthDipper $\dagger$

$\mathrm{Re} \quad$ Reinforcer

(1.0/1.0)

A. Directed at the Light

\begin{tabular}{|c|c|}
\hline Lite & Light \\
\hline $\mathrm{Ll}$ & $\begin{array}{l}\text { LightLeft } \\
(-/ .84)\end{array}$ \\
\hline $\mathrm{Lr}$ & $\begin{array}{l}\text { LightRight } \\
(-/ 1.0)\end{array}$ \\
\hline $\mathrm{Lb}$ & $\begin{array}{l}\text { LightBoth } \\
(-/ 1.0)\end{array}$ \\
\hline Lf & LightFlail $\dagger$ \\
\hline Lsnout & $\begin{array}{l}\text { LightSnout } \\
(-/ .80)\end{array}$ \\
\hline Ml & $\begin{array}{l}\text { MouthLight } \\
(-1.0)\end{array}$ \\
\hline
\end{tabular}

Upward movement of body to position where angle between floor and a straight line extending from bottom of ear to top of haunch is $30^{\circ}$ or more. Hindpaws within eight floor grids from wall behind bar, body facing bar. Frontpaws in air.

Rear upward facing bar; downward facing dipper.

Truncated bar rear: lifting of head/torso without lifting both front paws from floor.

Approach and come within one noselength of bar: do not code if other bar behavior follows. Usually coded during shaping.

Moving of snout into space defined by imaginary vertical planes extending from sides of bar to ceiling. No bar contact. Score first time break plane.

Moving of snout into space defined by imaginary vertical planes extending from sides of bar to floor. No bar contact. Score first time break plane.

Truncated Under. Moving of snout below, but not beneath, bar: code if next to bar.

Waving back and forth of front paw(s): either back and forth or side to side. Usually occurs if paw slips off bar.

Turn neck so that bottom of head faces bar when underneath bar.

\section{Dipper-Directed Components}

Snout inside dipper recess. Note: Use to collapse all dipper categories.

Both paws on dipper ledge.

Right paw on dipper ledge.

Left paw on dipper ledge.

Same body behavior as bar rear: position within eight floor grids of dipper, body facing dipper.

Code when rat lifts up facing dipper and lowers when facing bar.

Truncated dipper rear: same body position as BarLift, but facing dipper.

Bow head up and down while facing dipper.

Biting edge/ledge of dipper.

Contact dipper ledge/edge with mouth.

Receipt of reinforcer by subject. Can also be coded as Drinking to denote that water presented at the dipper.

\section{Other-Directed Components}

Light contact with any part of the body except open mouth. Note: use to collapse all light categories.

Contact light above bar with left paw.

Contact light with right paw.

Contact light with both paws.

Flail at light rather than bar.

Contact light with snout.

Contact light with open mouth: include licking, but not biting, the light. 


\section{APPENDIX (Continued)}

$\begin{array}{lll}\text { BLite } & \begin{array}{l}\text { BiteLight } \dagger \\ (-/ 1.0)\end{array} & \text { Contact light with teeth. } \\ \text { Orient } & \begin{array}{l}\text { Orient } \\ (-/ .91)\end{array} & \text { Approach and come within one noselength of light. }\end{array}$

B. Directed at Any Part of Box Unless Noted Otherwise

\begin{tabular}{|c|c|c|}
\hline $\mathrm{Bx}$ & Boxtop & Contacting top of chamber with any part of body. \\
\hline Bw & BiteWall $\dagger$ & Contact wall behind bar/between bar and dipper with teeth. \\
\hline Def & Defecate $\dagger$ & Defecate. \\
\hline $\mathrm{Fa}$ & Fall $\dagger$ & Lose balance while rearing. \\
\hline Flr & Floor*† & $\begin{array}{l}\text { Tap paw on floor next to bar either just before or between presses } \\
\text { with same paw. }\end{array}$ \\
\hline Frz & $\begin{array}{l}\text { Freeze } \\
(-11.0)\end{array}$ & Pause without motion for at least $1 \mathrm{sec}$ \\
\hline G & $\begin{array}{l}\text { Groom } \\
(1.0 / 1.0)\end{array}$ & Continuous rubbing, scratching, or biting of body or head. \\
\hline $\mathrm{Ht}$ & $\begin{array}{l}\text { HeadToss } \\
(1.0 /-)\end{array}$ & $\begin{array}{l}\text { At least two up and backwards movements of the head in } \\
\text { succession. }\end{array}$ \\
\hline $\mathrm{Li}$ & $\begin{array}{l}\text { Litter } \\
(-11.0)\end{array}$ & Contact litter beneath grid floor with snout or paws. \\
\hline Mo & $\begin{array}{l}\text { MouthOther } \\
(-11.0)\end{array}$ & Mouth contact with surface other than dipper, bar, or light. \\
\hline MWall & MouthWall $\dagger$ & $\begin{array}{l}\text { Mouth moving in contact with wall behind bar/between bar and } \\
\text { dipper. }\end{array}$ \\
\hline No & $\begin{array}{l}\text { NoseOther } \\
(-/ 1.0)\end{array}$ & Snout contact with surface other than dipper, bar, or light. \\
\hline Ro & $\begin{array}{l}\text { RearOther } \\
(1.0 / 1.0)\end{array}$ & $\begin{array}{l}\text { Same behavior as Bar Rear. Position: anywhere in box not speci- } \\
\text { fied by Bar or Dipper Rear. }\end{array}$ \\
\hline $\mathrm{Sp}$ & $\begin{array}{l}\text { Sleep } \dagger \\
(1.0)\end{array}$ & $\begin{array}{l}\text { Sit or lie with closed eyes while stationary. Usually seen during } \\
\text { Baseline, Deprived, and Extinction conditions. }\end{array}$ \\
\hline Wa & $\begin{array}{l}\text { Walk } \\
(1.0 / 1.0)\end{array}$ & $\begin{array}{l}\text { Move with at least three paws on ground without contacting any } \\
\text { other surface. }\end{array}$ \\
\hline $\mathrm{Wb}$ & WallBoth & Paws contacting metal wall surface on either side of bar. \\
\hline Wl & $\begin{array}{l}\text { WallLeft* } \\
(1.0 / 1.0)\end{array}$ & Left paw contacting metal wall surface on either side of bar. \\
\hline Wr & $\begin{array}{l}\text { WallRight* } \\
(1.0 / .71)\end{array}$ & Right paw contacting metal wall surface on either side of bar. \\
\hline $\mathrm{Y}$ & Yawn $\dagger$ & Open mouth and yawn. \\
\hline
\end{tabular}

*Paw variants. †Additions in Experiment 2.

(Manuscript received August 25, 1993; revision accepted for publication April 28, 1994.) 